\title{
PÍO DEL RÍO HORTEGA. UNA FIGURA EGREGIA DE LAS CIENCIAS NEUROLOGICAS
}

\author{
Javier Vargas Castrillón, Isabel Gallego Villaescusa, \\ María del Carmen García-Andrade Fernández, \\ Eugenia Jareño Borrego, Luis Carretero Albiñana \\ Servicio de Anatomia Patológica del Hospital Universitario Santa Cristina de Madrid
}

\begin{abstract}
The article describes the Santiago Ramón y Cajal and Pio del Rio Hortega scientific career and the relevance of their discoveries in neurology. The actual status of research on neurology is described

KEY WORDS Santiago Ramón y Cajal. Pio del Río Hortega. Central Nervous System Structure.
\end{abstract}

RESUMEN El artículo describe la trayectoria científica de Santiago Ramón y Cajal y Pío del Río Hortega y la trascendencia de sus descubrimientos en las ciencias neurológicas, asi como el estado actual de la investigación neurológica.

PALABRAS CLAVE Santiago Ramón y Cajal. Pío del Río Hortega. Estructura del Sistema Nervioso Central.

\section{Introducción}

El descubrimiento del microscopio óptico abrió sin duda un campo nuevo en el conocimiento humano y posibilitó el conocimiento de la estructura de lo más pequeño que permanecia hasta entonces inaccesible al conocimiento humano. Uno de los campos en que el microscopio posibilitó importantes desarrollos fue en la descripción morfológica de la estructuras del cuerpo humano y sus enfermedades, dando lugar al desarrollo de la Histología y de la Anatomía Patológica, disciplinas centrales y básicas en el despliegue de conocimientos que ha dado lugar a la Medicina Cientifica moderna.

El conocimiento detallado de la estructura de los diferentes órganos, sistemas y aparatos del cuerpo humano es $\sin$ duda requisito indispensable para conocer su funcionamiento y corregir sus desarreglos. En este contexto la figura de Don Pío del Río Hortega es sin duda una figura señera no sólo en la Medicina Española, sino también en el contexto de la Medicina Mundial y en concreto en todo el desarrollo de las diferentes ramas de las ciencias neurológicas.

A finales del siglo XIX la histología general del cuerpo humano estaba bastante bien pergeñada, pero la estructura microscópica y la organización general del sistema nervioso central (SNC), permanecian elusivas al esfuerzo investigador de los histólogos. Tuvo que ser un español universal, Don Santiago Ramón y Cajal quién utilizando las tinciones argéntinas desarrolladas en Italia por Camilo Golgi, para estudiar el SNC, consiguió no sólo desentrañar su estructura sino desarrollar una teoría general sobre el funcionamiento jerarquizado del SNC, conocida como teoria neuronal que todavía hoy sigue siendo el paradigma en el que se desenvuelven las Ciencias Neurológicas.

\section{La escuela histológica del Doctor Santiago Ramón y Cajal}

Sobre la gran figura del Doctor Santiago Ramón y Cajal se ha dicho y se ha escrito casi todo, pues es él quien consigue conceptuar la estructura básica del SNC y su funcionamiento y además consigue fundar y desarrollar una formidable escuela histológica que logra reunir a lo que posiblemente ha sido el grupo investigador mas brillante de la historia de la Ciencia Española: Lorente de No, Achúcarro, Tello y el propio Río Hortega desarrollaron bajo la dirección de Don Santiago Ramón y Cajal un verdadero torrente de inventiva, dedicación y descubrimiento que pusieron a España a la cabeza de la investigación en ciencias neurológicas, con el mérito añadido de ser un milagro creador en un páramo como el que era la ciencia española de comienzos de siglo XX (recordemos el deprimente "que inventen ellos" del por otro lado admirable Miguel de Unamuno). 
El trabajo de todos estos ilustres investigadores rindió frutos enormes en el estudio general del SNC, en el conocimiento de las redes neuronales y la sinapsis y en el descu- brimiento y clasificación de las diferentes células que componen el tejido de soporte del SNC: la glía (astroglia, oligodendroglía, microglía) (Fig.1).

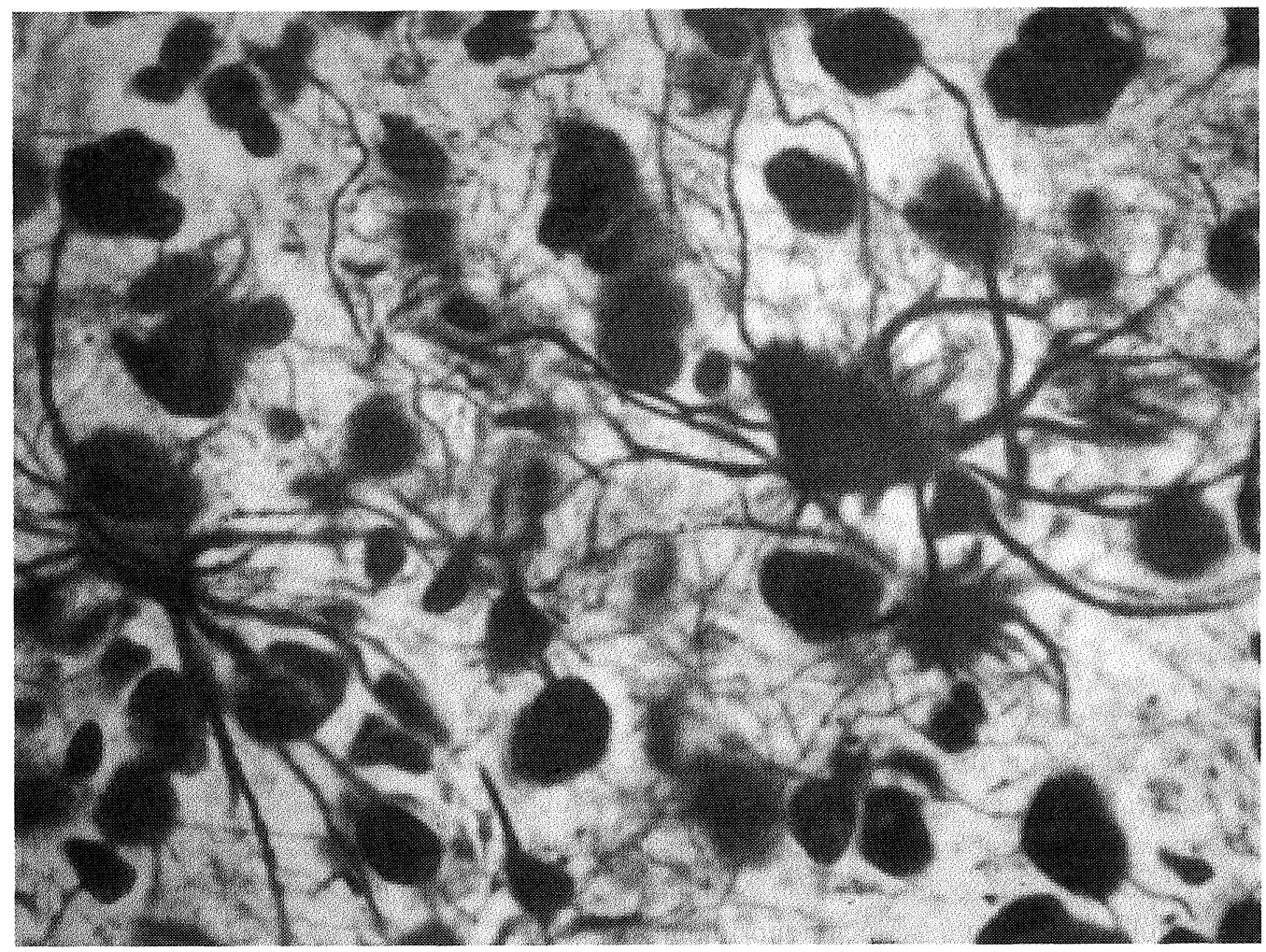

Figura 1. Microglia.

Adviertase la presencia de múltiples microglias redondeadas inmersas en una funda matriz fibrilar neuroglial. Foto original Rio Hortega

La actividad de este grupo de personas alcanzó un grado eximio que se simbolizó en la concesión del premio Nóbel de Medicina a su líder Don Santiago Ramón y Cajal. Desgraciadamente lo que pudo ser el inicio del predominio definitivo de España en el estudio del SNC, quedó trágicamente truncado por el desarrollo político de España que culminó en la guerra civil y la victoria de las tropas franquistas, hecho que propició la salida hacia el exilio de la mayoria de las figuras anteriormente citadas.

\section{Don Pío del Río Hortega}

Don Pío del Río Hortega (1882-1945) tuvo una dilatada e intensa carrera profesional que le llevó desde su Castilla natal a los más altos puestos que en la época en que vivió existian para la investigación médica en España. Comenzó en 1911 como profesor auxiliar en Histología y Anatomía Patológica en la Facultad de Medicina de la Universidad de Valladolid y de ahi, y completando su formación con estancias en Paris, Berlín y Londres entre 1913 y 1915, llegó a dirigir el laboratorio de Anatomía Patológica del Instituto Ramón y Cajal en 1920 y finalmente llegó en 1931 a director del Instituto Nacional de Investigación sobre el cáncer. Desgraciadamente la guerra civil y la post-guerra le llevaron al exilio rompiendo completamente una prominente actividad investigadora.

Durante su vida como investigador publicó más de 100 artículos científicos en importantes revistas nacionales e internacionales, así como varios libros y capítulos de libros. También desarrolló una intensa actividad docente dictando múltiples clases y conferencias de alto nivel.

ARBOR CLXXXI 714 JULIO-AGOSTO (2005) 215-219 ISSN: 0210-1963 
Sus contribuciones más importantes desde el punto de vista de la histología residieron en sus estudios sobre las conexiones neuronales y la participación de la glia a la estruc- tura del SNC. En anatomía patológica destacó por sus investigaciones sobre las características microscópicas de los diferentes tumores cerebrales (Fig.2).

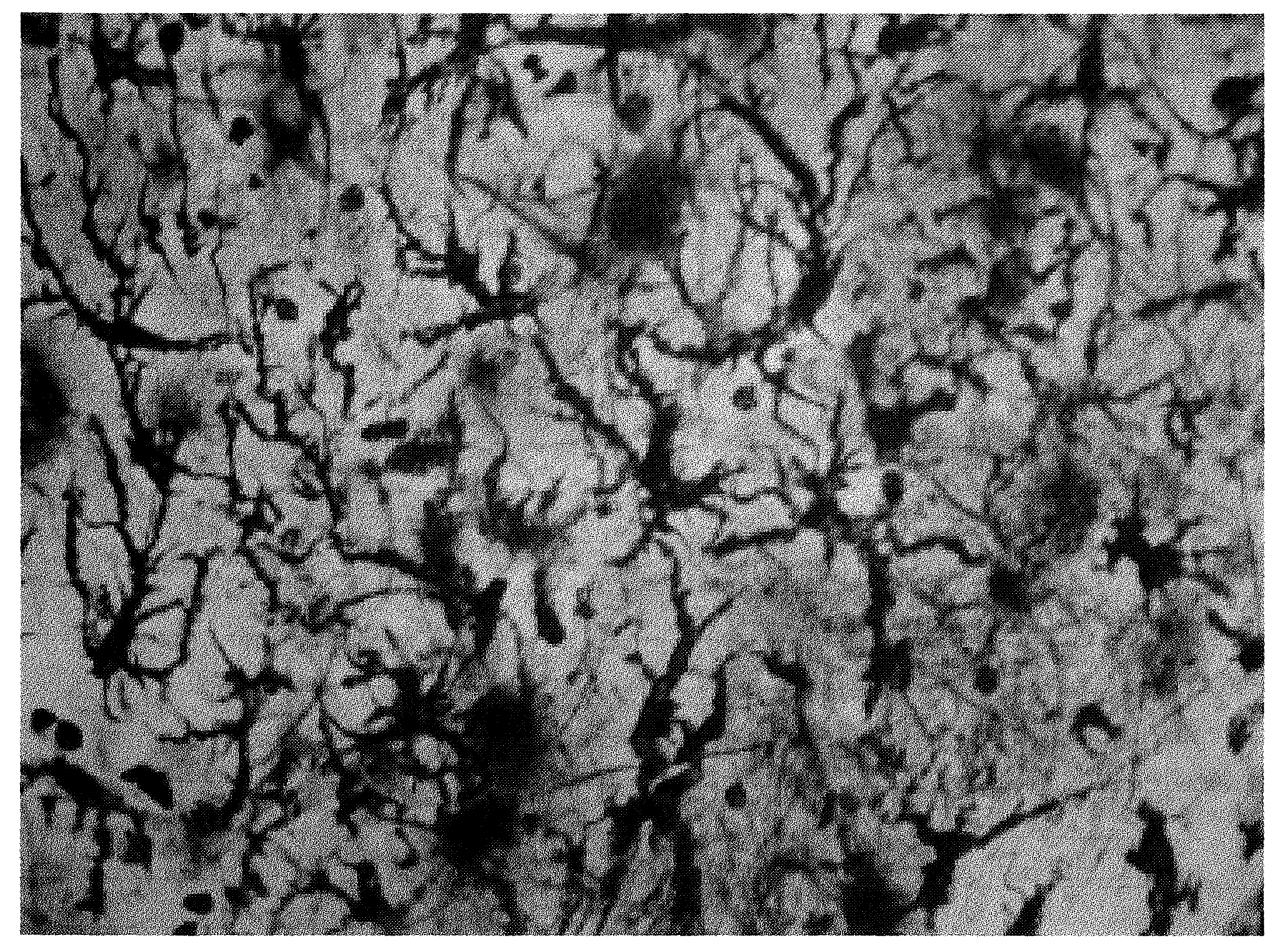

Figura 2. Glioma (Astrocitoma)

Tinción argéntica de Astrocitoma Humano. A destacar la presencia de astrocitos neoplasicos con múltiples prolongaciones fibrilares, Foto original. Río Hortega

Hombre brillante destacó como docente y además, debido a su minuciosidad, desarrolló y mejoró las técnicas de impregnación argéntica diseñadas por Don Santiago Ramón y Cajal lo que ayudó a precisar la estructura intima del SNC y la interrelaciones entre las neuronas y sus prolongaciones y la neurologia.

Posiblemente sin la súbita interrupción de su actividad debido a la guerra civil su aportación se hubiera completado y hubiera brillado aún más en el panorama de la ciencia moderna. Desgraciadamente en las manos de los hombres de ciencia no está el controlar el devenir político de las naciones en que viven. La nueva realidad europea y el horizonte de paz y progreso que se dibujan hace que la nueva generaciones de investigadores españoles gocen de una posición infinitamente mejor que la que tenía Don Pío del Río Hortega, solamente debemos esperar que se acompañe también de un talento tan extraordinario como el que poseia el gran investigador castellano.

\section{La neurología de ayer y de hoy}

El trabajo de toda la escuela de investigadores españoles dejó como herencia una teoría general de la estructura del SNC y de su funcionamiento conocida como teoría neuronal, que todavía sigue siendo el eje de la investigación neurológica moderna. ¿Pero adónde y porqué medios se dirigen las investigaciones neurológicas? La respuesta a esta pregunta nos introduce directamente en territorios fascinantes puesto que la introducción de nuevas técnicas investigadoras ha abierto vías profundas de conocimiento de la actividad del SNC que nos permitirán conocer como funciona la totalidad del sistema y sus diferentes partes para desarro- 
Ilar tratamientos específicos a la gran cantidad de afecciones que asientan en el cerebro y en el resto de los órganos del SNC.

Desde el punto de vista estructural histológico y anatomopatológico el descubrimiento de la inmunohistoquímica y de las diferentes técnicas de patología molecular han permitido la detección en cortes histológicos de numerosas sustancias, genes y organismos infectivos, lo que ha provocado que la histologia y la anatomía del SNC se hagan, en cierto modo, funcionales.

Un ejemplo paradigmático es la detección de los priones y otros "virus lentos" mediante inmunohistoquímica y patología molecular, lo que ha permitido profundizar en los mecanismos de la infección y en la manera en que afectan a las células del SNC produciendo en última instancia la sintomatología clínica de los pacientes. Virus como el virus del Herpex pueden también ser detectados mediante inmunohistoquímica, así como numerosos antígenos de gran utilidad como antígenos proliferativos como el Ki 67 que mejoran el diagnóstico de estos tumores.

También la gran mejoria en técnicas de imagen como el TAC y la Resonancia nuclear Magnética son la gran ayuda en clínica, y la introducción de técnicas funcionales con radioisótopos como el PET, marcan la pauta investigadora puesto que ayudan a conocer que porciones del SNC se activan en diferentes situaciones clínicas y patológicas, ayudando a desarrollar un mapa funcional del SNC. La tendencia actual de las investigaciones neurológicas parece desarrollarse en este contexto de conocer en profundidad la función de las diferentes áreas neuronales mediante técnicas dinámicas que identifiquen las zonas metabólicamente activas en cada una de las situaciones en que se desarrolla la actividad cerebral.

\section{Conclusión}

La actividad investigadora del Doctor Pío del Río Hortega y de sus compañeros sembró las semillas de lo que hoy es un árbol en pleno desarrollo, esto es el conocimiento detallado y preciso del funcionamiento del cerebro humano, tal vez la joya más preciosa que el desarrollo evolutivo de la vida ha producido en la tierra. Este conocimiento abrirá paso a nuevas terapéuticas que controlen a enfermedades tan devastadoras como por ejemplo la esquizofrenia o la enfermedad de Alzheimer.

Es sin duda un orgullo y una gran satisfacción que el comienzo de este magnifico y apasionante camino emprendido por los investigadores neurológicos comenzara a ser desarrollado compatriotas tan ilustres y geniales como Doctor Pío del Río Hortega, sin duda su talento y dedicación contribuyeron y seguirán contribuyendo a que el papel de la Ciencia española sea cada vez mayor en el concierto internacional. 


\section{BIBLIOGRAFÍA}

Cajal y la anatomía patológica española, una historia compartida. H. Oliva Aldámiz

Del Río-Hortega, P. (1919) «El tercer elemento de los centros nerviosos. 1. La microglia. 2. intervención de la microglia en los procesos patológicos. 3 . naturaleza probable de la microglian. Boletín de la Sociedad Española de Biología, 9, 69-120.

Del Río-Hortega, P. \& Penfield, W. (1928) "Cerebral cicatriz: The reaction of neuroglia to brain woundsin. Archives of Neurology and Psychiatry (Chicago), 19,180-181.

Del Rio-Hortega, P. (1932) Microglía in Penfield's Cytology and Celular Pathology of the Nervous System, Vol. 2 pp. 483-534, Hoeber, New York.

Erisi MM. Herpes simplex encephalitis. An inmunohistological study of the distribution of viral antigen within the brain. J. Neurol Sci 1982, 54:209-226.

Castellani RJ, Parchi P, Madoff L, Gambetti $P$, McKeever P, Biopsy diagnosis of Creutzfieldt-Jakob disease by Western blot. A case report. Hum Pathol 1997, 28: 623-6.

Murayama S, Bouldin TW, Suzuki K. "Inmunocytochemical and ultrastructural studies of eosinophilic granular bodies in astrocytic tumorsn. Acta Neuropathol (Berl ) 1992, 83: 408-414.

ARBOR CLXXXI 714 JULIO-AGOSTO (2005) 215-219 ISSN: 0210-1963 